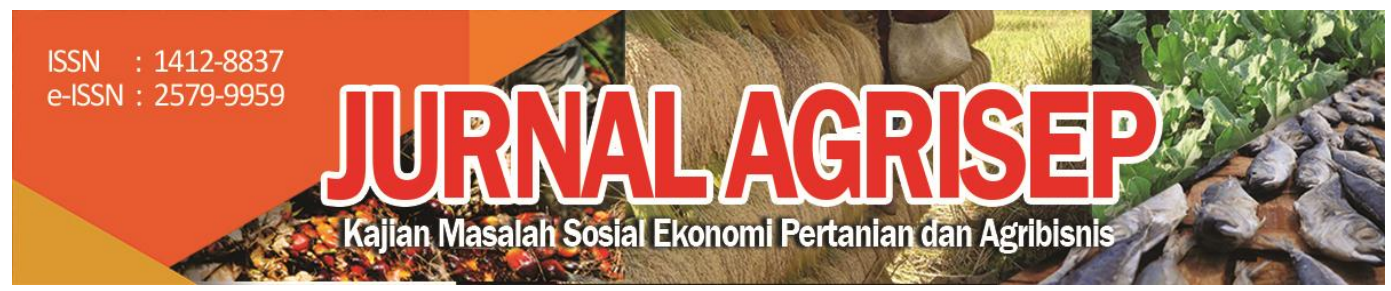

DOI 10.31186/jagrisep.17.1.107-118

\title{
ANALISIS KELAYAKAN FINANSIAL PEMBIBITAN SAPI PERANAKAN ONGOLE POLA GADUHAN
}

\section{An Analysis of Financial Feasibility of Hynbrid Ongole Cattle Breeding Gaduhan Pattern}

\author{
Ridha Rizki Novanda \\ Jurusan Sosial Ekonomi Pertanian, Fakultas Pertanian, Universitas Bengkulu \\ Email: ridha.rizki.novanda@gmail.com
}

\begin{abstract}
Gaduhan is one of agribusiness pattern committed by farmers for assistance in his business capital. Andini Muyo livestock group has received government assistance in the form of funds to implement PSBP and PPBB. Cattle breeders were given to members' group by profit-sharing system. This research was aimed at analysing the financial feasibility of cattle breeder bussiness on "penggaduh" system after receiving two types of PSBP assistances and its sensitivity. Data dari fourty seven respondents censused were analysed descriptive and quantitively using NPV, IRR, PP, Net B/C, and Gross B/C indicators. The results showed that the gaduhan system was unfeasible financially.
\end{abstract}

Keywords: Feasibility, Gaduhan, PSBP, PPBB

\section{ABSTRAK}

Pola gaduhan merupakan salah satu pola agribisnis yang dilakukan oleh petani untuk mendapatkan bantuan modal dalam mengupayakan usahanya. Kelompok ternak Andini Mulyo menerima bantuan dari pemerintah berupa dana untuk melaksanakan PSBP dan PPBB. Indukan sapi diberikan kepada anggota yang dengan sistem bagi hasil. Tujuan penelitian ialah menganalisis kelayakan usaha peternak secara finansial usaha penggaduh yang hanya setelah menerima kedua macam bantuan PSBP dan PPBB, Data dari 47 responden disensus dan dianalisis secara deskriptif dan kuantitatif dengan menggunakan indikator NPV, IRR, PP, Net B/C, Gross B/C). Aspek finansial dinilai tidak layak.

Kata Kunci: Kelayakan, Gaduhan, PSBP, PPBB 


\section{PENDAHULUAN}

Indonesia memiliki angka impor bakalan sapi yang cukup besar terhadap dari tahun ketahun. Tingginya kebutuhan bakalan sapi mengindikasikan bahwa kurang terpenuhinya bakalan sapi di Indonesia. Tercatat oleh KEMENTAN (2013), bahwa nilai impor bakalan yang nilainya sebesar $130.021 .422 \mathrm{~kg}$ atau setara dengan USD 338.399.338 meningkat sebesar 58 \% dari tahun sebelumnya. Tingginya nilai impor bakalan sapi haruslah sangat diperhatikan oleh pemerintah. Sehingga dapat terwujud target impor daging dan bakalan sapi pada sebesar $10 \%$ dari kebutuhan konsumsi masyarakat.

Berdasarkan fakta dilapangan bahwa tingginya impor bakalan akan mengancam program swasembada daging sapi. Jumlah populasi produksi, dan produktifitas dalam skala rumah tangga serta masih rendahnya tingkat pengolahan dan hasil pemasaran produksi merupakan kondisi peternakan rakyat. Tujuan pemeliharaan sapi dipeternakan rakyat bukan berdasarkan siklus produksi saja, sehingga sewaktu-waktu peternakan rakyat membutuhkan uang tunai maka sapi betina produktif yang dimiliki dapat dijual. Sebagian besar bibit sapi dijual baik didalam kota maupun luar kota bahkan luar pulau. Hal ini mengakibatkan rumah potong hewan (RPH) kesulitan memperoleh sapi siap potong, sehingga sapi betina produktif dipotong untuk memenuhi kebutuhan daging masyarakat setempat. Pelarangan pemotongan sapi betina produktif dan penjualan pengiriman bibit sapi mengakibatkan sapi betina produktif memiliki nilai jual yang lebih rendah dibandingkan sapi jantan. Hal ini menyebabkan tingginya pemotongan sapi betina produktif secara nasional.

Pemotongan sapi betina produktif sebenarnya sudah dilarang berdasar UU No. 18/2009 dapat dikenakan sanksi administrasi maupun hukuman kurungan yang cukup berat. Namun sampai saat ini belum sepenuhnya diterapkan. Pemahaman dan kesadaran dari seluruh masyarakat masih beragam sehingga perlu dilakukan tindakan konkrit yang lebih operasional. Guna penguatan sapi betina produktif, perlu adanya pihak terkait yang mampu memberikan bantuan dana kepada peternak yang memerlukan uang dan akan menjual sapi betina produktif mereka. Oleh karena itu pada tahun 2012 diadakan program Penyelamatan Sapi Betina Produktif (PSBP). PSBP merupakan program yang dilakukan untuk menurunkan angka kematian sapi betina produktif. Sapi betina produktif merupakan salah satu komoditas yang harus diselamatkan, hal ini dikarenakan sapi betina produktif merupakan input penting penghasil bakalan sapi. Sehingga program ini ditujukan untuk sektor peternakan sapi yang akan memperkokoh subsektor pembibitan sapi yang nantinya diharapkan akan menghasilkan bakalan dan menurunkan angka impor bakalan. Salah satu kebijakan penting Kementerian Pertanian adalah swasembada daging yang berbasis sumber daya lokal. Untuk itu melalui 
program Penyelamatan Sapi Betina Produktif diharapkan indukan produktif khususnya sapi lokal dapat diberdayakan untuk menghasilkan bakalan lokal yang berbasis sumber daya domestik.

Program Penyelamatan Sapi Betina Produktif dilakukan oleh beberapa Provinsi di Indonesia khususnya D.I Yogyakarta yang turut serta melakukan program Penyelamatan Sapi Betina Produktif (PSBP). PSBP dilakukan oleh Provinsi D.I Yogyakarta dalam rangka untuk mendukung program swasembada daging sapi 2014 dan meningkatkan populasi sapi potong diwilayah D.I Yogyakarta yang nilainya cenderung menurun dari tahun 2011 hingga tahun 2013 (Gambar 2). Program ini diimplementasikan ke wilayah sentra pembibitan sapi lokal yaitu Kabupaten Gunung Kidul. Kabupaten Gunung Kidul merupakan wilayah sentra pembibitan sapi PO maupun wilayah sentra penghasil daging sapi di D.I Yogyakarta.

Dinas Peternakan Kabupaten Gunung Kidul, D.I. Yogyakarta, terus melakukan penyelamatan dan mempertahankan ternak unggulan lokal berupa sapi lokal berbangsa Peranakan Ongole (PO). Hal ini dilakukan sesuai dengan program PSBP tahun 2012 dan program intensifikasi pembibitan ternak lokal PO untuk mencapai Gunung Kidul sebagai gudang bakalan lokal pada tahun 2020 dan juga mendukung program PSDS 2014. Program PSBP di wilayah Gunung Kidul berupa pemberian dana bantuan sebesar Rp 500.000.000,- untuk setiap kelompok ternak yang ditujukan untuk pembelian indukan lokal. Akan tetapi, program PSBP di Gunung Kidul tidaklah berdiri sendiri, terdapat program lainnya yang di implementasikan tahun 2014 yaitu Program Penguatan Betina Bunting (PPBB).

Sistem pemberian penguatan modal tidak hanya sebagai bantuan belaka, akan tetapi mengharapkan pengembalian atas usahanya yaitu berupa bagi hasil untuk penguatan kelembagaan peternakan. Gaduhan merupakan salah satu pola yang banyak dilakukan oleh peternak anggota kelompok dengan bantuan modal tersebut.

Gaduhan merupakan salah satu kegiatan bagi hasil yang dilakukaan oleh kelompok Andini Mulyo dengan anggota-anggotanya. Pemerintah sebagai penyalur dana PSBP dan PPBB, dan kelompok ternak mengorganisir penggunaan dana untuk kemajuan kelompoknya dan memberikan bantuan modal kepada para peternak sebagai penggaduh. Menurut Mubyarto (1995) dalam Zulfamita (2009), modal merupakan faktor yang menentukan keberhasilan pembangunan pertanian. Adanya permodalan bagi usaha ternak tradisional salah satunya adalah dengan bantuan pemerintah berbentuk gaduhan. Simatupang et al. (1994) dalam Zulfamita (2009) juga menyatakan bahwa faktor-faktor yang dapat mendorong munculnya sistem gaduhan adalah karena belum berkembangnya lembaga keuangan desa, bentuk usaha ternak masih bersifat keluarga, masih banyaknya keluarga yang berpendapatan rendah, desa yang bersangkutan memiliki potensi produksi yang cukup. Hal ini 
menunjukkan bahwa keberadaan ternak penting dalam menopang kehidupan rumah tangga tani di pedesaan. Oleh karena itu, akselerasi pelaksanaan program PSBP dan PPBB di kelompok Andini Mulyo dan Kabupaten Gunung Kidul sangat bergantung terhadap usaha pola gaduhan dari peternak-peternak anggota kelompok. Berangkat dari diskusi ini, tujuan penelitian ini adalah menganalisis kelayakan finansial usaha penggaduh dengan bantuan modal PSBB dan PPBB.

\section{METODE PENELITIAN}

Penelitian dilakukan di Kecamatan Playen, Kabupaten Gunung Kidul, Yogyakarta. Penelitian dilakukan pada peternak rakyat pembibitan sapi PO rakyat di kelompok Andini Mulyo. Jenis data yang digunakan yaitu data kuantitatif maupun kualitatif. Sumber datanya yaitu primer dan data sekunder yang diambil sesuai dengan kebutuhan penelitian. Data primer merupakan data yang diambil secara langsung baik itu melalui kuisioner maupun wawancara mengenai biaya-biaya usaha ternak, penggunaan input produksi dan proses pemeliharaan. Pemilihan Gunung Kidul sebagai Kabupaten yang ditunjuk di lakukan secara Purposive dengan alasan karena Gunung Kidul merupakan sentra utama produksi sapi potong di Daerah Istimewa Yogyakarta. Analisis yang dilakukan dalam penelitian ini dilakukan secara kuantitatif dan kualitatif. Analisis kuantitatif digunakan untuk mengkaji kelayakan finansial usaha pembibitan sapi $\mathrm{PO}$ pada peternakan rakyat berdasarkan kriteria kelayakan investasi yaitu NPV, IRR, dan Net B/C Ratio, Gross B/C, Payback Periode.

\section{Net Present Value (NPV)}

$$
N P V=\sum_{t=0 / 1}^{n} \frac{\mathrm{Bt}-\mathrm{Ct}}{(1+\mathrm{i})^{\mathrm{t}}}
$$

\section{Gross Benefit-Cost Ratio (Gross B/C)}

$$
\operatorname{Gross} \frac{B}{C}=\sum_{t=0 / 1}^{n} \frac{\frac{B t}{(1-i)^{t}}}{\frac{C t}{(1-i)^{t}}}
$$

\section{Net Benefit Cost Ratio (Net B/C Ratio)}

$$
\text { Net } \frac{B}{C}=\sum_{t=0 / 1}^{n} \frac{\frac{B t-C t}{(1-i)^{t}}}{\frac{B t-C t}{(1-i)^{t}}}
$$

dimana Bt = Manfaat pada tahun $\mathrm{t}, \mathrm{C} t=$ Biaya Pada Tahun $\mathrm{t}, \mathrm{T}=$ tahun kegiatan bisnis, $\mathrm{i}=$ Tingkat DR $(\%)$, dan $\frac{1}{(1+i)^{t}}=$ Discount Factor $(\mathrm{DF})$ pada tahun ke-t 


\section{Internal Rate Of Return (IRR)}

$$
I R R=i_{2}+\frac{N P V_{1}}{N P V_{1}-N P V_{2}} x\left(i_{2}-i_{1}\right)
$$

dimana $\mathrm{i}_{1}=$ Discount rate yang menghasilkan NPV Positif terkecil, $\mathrm{i}_{2}=$ Discount rate yang menghasilkan NPV negatif terbesar, $\mathrm{NPV}_{1}=\mathrm{NPV}$ positif terkecil, dan $\mathrm{NPV}_{2}=\mathrm{NPV}$ negatif terbesar

\section{HASIL DAN PEMBAHASAN}

\section{Gambaran Umum}

Peternak respondek berasal dari umur diatas 30 tahun (Tabel 1). Peternak responden tidak ada yang berusia dibawah 30 tahun. Sementara peternak dengan rentah usia 30 hingga 49 tahun memiliki persentase sebesar $43 \%$. Sementara itu peternak dengan usia 50 tahun hingga 69 tahun menduduki peringkat dua dengan persentase sebesar $41 \%$ dan peternak dengan usia 70 tahun keatas sebesar $15 \%$.

Tingkat pendidikan terendah ialah Sekolah Dasar dan tingkat pendidikan tertinggi ialah sarjana. Hampir setengah dari respoden merupakan lulusan dari Sekolah Dasar dengan persentase sebanyak 48 \% (Tabel 1). Sementara itu $25 \%$ responden ialah lulusan dari Sekolah Menengah Pertama dan 17 \% lainnya ialah lulusan sekolah menengah Atas. Selain itu $16 \%$ responden merupakan lulusan dari perguruan tinggi dengan persentase $7 \%$ jenjang diploma tiga dan $5 \%$ jenjang sarjana.

Mata pencaharian utama dari responden mayoritas ialah sebagai petani tanaman palawija. Mata pencaharian responden mayorotas ialah petani dengan proporsi sebesar $67 \%$. Sementara wiraswasta menduduki posisi selanjutnya dengan proporsi $15 \%$. Selain itu responden yang bermata pencarian sebagai PNS memiliki proporsi sebesar $9 \%$, Pensiunan memiliki proporsi sebesar $4 \%$, sopir memiliki proporsi sebesar $2 \%$, dan Perangkat Desa memiliki proporsi sebesar $2 \%$.

Pengalaman beternak kelompok Andini Mulyo paling rendah ialah 3 tahun dan tertinggi diatas 50 tahun. Pengalaman peternak tertinggi ialah $38 \%$ diusia antara 27 tahun hingga 38 tahun. Sementara itu paling terendah yaitu usia 39 tahun hingga 50 tahun dengan persentase $8 \%$ (Tabel 12). Berdasarkan data tersebut dapat disimpulkan bahwa pengalaman beternak responden mayoritas diusia 27 tahun hingga 38 tahun hingga 38 tahun. Sementara responden yang berpengalaman selama 39 tahun hingga 50 tahun memiliki jumlah yang kecil. 
Tabel 1. Profil Responden

\begin{tabular}{|c|c|c|c|}
\hline $\mathrm{No}$ & Karakteristik & Jumlah & persentase $(\%)$ \\
\hline \multirow[t]{5}{*}{1} & Umur (Tahun) & & \\
\hline & $<30$ tahun & 0 & 0 \\
\hline & $30<x<50$ & 27 & 44 \\
\hline & $50<x<70$ & 25 & 41 \\
\hline & $\geq 70$ & 9 & 15 \\
\hline \multirow[t]{6}{*}{2} & Pendidikan & & \\
\hline & SD & 29 & 48 \\
\hline & SMP & 15 & 25 \\
\hline & SMA/SPG & 10 & 16 \\
\hline & D3 & 4 & 7 \\
\hline & S1 & 3 & 5 \\
\hline \multirow[t]{7}{*}{3} & Mata Pencaharian & & \\
\hline & Petani/buruh tani & 41 & 67 \\
\hline & Sopir & 1 & 2 \\
\hline & Pensiunan & 3 & 4 \\
\hline & Wiraswasta & 9 & 15 \\
\hline & PNS & 5 & 9 \\
\hline & Perangkat Desa & 1 & 2 \\
\hline \multirow[t]{6}{*}{4} & Pengalaman Beternak & & \\
\hline & $3 \leq X \leq 14$ & 13 & 21 \\
\hline & $15 \leq X \leq 26$ & 13 & 21 \\
\hline & $27 \leq X \leq 38$ & 23 & 38 \\
\hline & $39 \leq X \leq 50$ & 5 & 8 \\
\hline & $51 \leq X$ & 8 & 13 \\
\hline
\end{tabular}

\section{Analisis Kelayakan Finansial}

\section{Arus kas (Cashflow)}

Komponen inflow pada usaha penggaduh berasal dari nilai penjualan pedet, nilai sisa, nilai penjualan kotoran, bantuan paket pakan dan kesehatan, bantuan PPBB. Inflow memiliki nilai yang flukluatif dari tahun ketahun. Pada tahun pertama, nilainya tidak begitu besar. Hal ini dikarenakan tidak terdapat penjualan pedet pada tahun pertama. Begittu juga dengan tahun ke-5, tidak terdapat penjualan pedet (Tabel 2).

Kekosongan penjualan pedet diakibatkan oleh calving interval yang terlalu panjang serta services per conception yang terlalu tinggi. Kondisi biologis ini sangat menentukan penerimaan usaha pembibitan. Nilai inflow dinilai sangat rendah untuk perkepala keluarga ternak hingga tahun ke-5 dengan rata-rata Rp 9.949756,73 per kepala keluarga ternak yang dapat menjual pedetnya dan nilai tersebut belum termasuk pengeluaran atas biaya-biaya dan bagi hasil. Hal ini 
sejalan dengan penelitian Atmakusuma et al. (2011), Usaha peternakan rakyat skala kecil memiliki penerimaan yang relative rendah tetapi masih terus dijalankan oleh peternak rakyat.

\section{Tabel 2. Inflow}

\begin{tabular}{rrrr}
\hline Tahun & Inflow $(\mathrm{Rp})$ & Nilai bagi hasil & \multicolumn{1}{l}{ Nilai BEP } \\
\hline 1 & 316.089 .800 & - & 13.465 .311 \\
2 & 650.352 .354 & 94.449 .960 & 13.465 .297 \\
3 & 666.875 .761 & 94.449 .960 & 13.465 .301 \\
4 & 750.946 .495 & 94.449 .960 & 13.465 .284 \\
5 & 606.935 .161 & - & 13.465 .247 \\
6 & 1.111 .417 .720 & 124.950 .000 & 13.465 .221 \\
7 & 1.904 .779 .098 & 153.000 .000 & 13.465 .218 \\
\hline
\end{tabular}

Komponen outflow atau biaya yang dikeluarkan dibagi atas beberapa hal yaitu biaya investasi dan biaya operasional.

\section{Biaya investasi}

Biaya investasi yang dikeluarkan penggaduh ialah kandang, arit, ember $20 \mathrm{~L}$, ember $14 \mathrm{~L}$, ember $12 \mathrm{~L}$, bak 20L, sekop, garpu, lampu, alat angkut, instalasi PAM, instalasi Listrik. Dari keseluruhan investasi yang dikeluarkan penggaduh, di dapatkan nilai $\mathrm{Rp}$ 298.794.240,- atau rata-rata perkeluarga tenak mengeluarkan sebesar Rp 4.897.774,43. Dengan biaya investasi tertinggi sebesar ialah pada kandang.

Nilai investasi tersebut relative kecil, hal ini disebabkan karena indukan sapi yang merupakan komponen utama investasi tidak dikeluarkan oleeh keluarga ternak melainkan berdasarkan subsidi pemerintah. Oleh karena itu usaha ternak pola gaduhan ini tidak memiliki biaya investasi indukan. Keunggulan program gaduhan ini berada pada poin investasi. Terciptanya keluarga peternak Karena hibah bantuan sapi indukan yang mereka dapatkan. Bantuan modal merupakan salah satu jalan keluar dalam mendorong usahapembibitan rakyat. Berdasarkan hasil penelitian terdahulu dari Widianti (2012), bantuan modal dengan masa tenggang 4 tahun dan bunga $4 \%$ dinilai layak. Namun pendapatannya masih rendah. Penelitian Rusdiana (2013) dan Widianti (2012) mengindikasikan bahwa tanpa bantuan modal dengan bunga yang rendah, usahaternak pembibitan rakyat tidak dapat berkembang dengan baikBiaya Operasional

\section{Biaya Tetap}

Biaya tetap yang dikeluarkan ialah beban listrik, beban air, perawatan kandang dan perawatan motor. Adapun nilai dari biaya tetapnya yaitu Rp 13.465.368,-. 


\section{Biaya Variabel}

Nilai dari biaya variabel dapat berbeda-beda di masing-masing responden. Hal ini diakibatkan karena perbedaan dalam penggunaan sumberdaya. Perbedaan penggunaan sumber daya ini dimaksudkan ialah proporsi sumber daya yang digunakan dalam proses budidaya dimasingmasing responden berbeda-beda. Biaya variabel diperhitungkan atas biaya tunai dan non tunai, hal ini dikarenakan terdapat input-input yang dikeluarkan tetapi tidak secara tunai melainkan secara non tunai. Biaya variabel yang dikeluarkan yaitu biaya pakan, biaya obat-obatan, dan biaya tenaga kerja.

\section{Tabel 3. Biaya Variabel}

\begin{tabular}{lcl}
\hline \multicolumn{1}{c}{ Biaya variabel } & $\begin{array}{c}\text { Rata-rata Nilai } \\
(\mathrm{Rp}) / \text { tahun }\end{array}$ & \multicolumn{1}{c}{ Keterangan } \\
\hline Biaya Pakan & 456.167 .080 & $\begin{array}{l}\text { Dikeluarkan peternak } \\
\text { Subsidi }\end{array}$ \\
Biaya Obat-obatan & - & Dikeluarkan peternak \\
Biaya tenaga kerja & 1.350 .752 .121 & \\
Total biaya Variabel & 1.806 .919 .201 & \\
Rata-rata biaya & $29.621 .626,27$ & \\
variabel/keluarga ternak & & \\
\hline
\end{tabular}

Tingginya biaya variabel yang dikeluarkan peternak akibat dari curahan biaya tenaga kerja dan biaya pakan yang relative besar pertahunnya. Besarnya biaya pakan disetiap jenisnya ialah berbeda-beda. Besarnya pun di hitung berdasarkan biaya yang diperhitungkan maupun biaya tunai. Komponen pakan yang dibeli juga diperhitungkan dengan pendekatan beberapa hal. Seperti pakan hijauan yang tidak dibeli diperhitungkan dari ongkos merumput yang dikonversikan kedalam nilai rupiah. Begitu juga dengan jerami yang tidak dibeli, nilainya diperhitungkan berdasarkan biaya angkut jerami di daerah tersebut. Sedangkan bekatul yang tidak dibeli, diperhitungkan berdasarkan ongkos giling beras. Biaya pakan terbesar dikeluarkan oleh hijauan. Hal ini disebabkan karena hijauan merupakan pakan pokok bagi sapi dengan jumlah yang besar.

Proses produksi membutuhkan biaya tenaga kerja. Biaya tenaga kerja diperhitungkan atas biaya tunai dan biaya oportunitasnya. Hal ini dikarenakan jenis tenaga kerja yang digunakan bukan hanya tenaga kerja yang berasal dari buruh tani, akan tetapi tenaga kerja berasal dari dalam keluarga adalah tenaga kerja utama. Manfat tenaga kerja dalam keluarga yang dikeluarkan untuk ikut serta di dalam usaha perbibitan ini dihitung 
dengan memperhatikan biaya opportunitasnya. Adapun kegiatan dari usaha perbibiitan ini ialah kegiatan merumput, kegiatan memberi pakan, kegiatan memandikan, kegiatan membersihkan kandang dan kegiatan memberikan minum.

\section{Biaya bagi hasil}

Hasil penjualan pedet dengan kelompok ternak Andini Mulyo dengan share $70 \%$ untuk penggaduh dan $30 \%$ untuk kelompok ternak. Kelompok ternak sebagai usaha kolektif yang memiliki sapi dan kandnag komunal dari program PSBP. Tujuan utama dari program tersebut ialah bukan hanya untuk menyelamatkan sapi betina saja, akan tetapi mengharapkan pertumbuhan kelompok sebagai lembaga perekonomian di pedesaan. Oleh karena itu bagi hasil merupakan kegiatan yang penting untuk diperhitungkan. Kegiatan bagi hasil ialah berdasarkan hasil penjualan, bukan bagi hasil keuntungan. Nilai bagi hasil tidak dikeluarkan pada tahun ke-1 dan ke-4. Hal ini disebabkan karena tidak ada penjualan pedet. Nilai total bagi hasil selama tujuh tahun ialah Rp 561.299 880,--

Share nilai gaduhan sebesar $30 \%$ untuk perkembangan kelompok dinilai sudah cukup baik dilakukan oleh kelompo ternak. Hal ini menunjukkan bahwa anggota elompok mampu memberikan $30 \%$ dari pendapatannya untuk kemajuan kelompok. Berbeda dengan pola gaduhan lainya yang mengangkat sistem bagi hasil dengan investor sebesar 50:50. Usaha sistem gaduhan ternak sapi dengan sistem 50:50, menyebabkan keuntungan yang diperoleh pemilik ternak lebih besar dibandingkan keuntungan yang diperoleh penggaduh, namun pola sistem gaduhan tetap terus dijalankan. Hal ini dikarenakan tidak ada pekerjaan lain untuk mendapatkan penghasilan tambahan (Septiandi 2013).

\section{Laba rugi}

Laba bersih yang diterima oleh responden memiliki rata-rata pertahun yang negatif (Tabel 2). Hal ini mengindikasikan bahwa penggaduh mengalami kerugian yang cukup besar. Sedangkan BEP menyatakan bahwa harga jual yang sesuai untuk pedet jantan ialah sebesar Rp 13.465.268,-. Oleh karena itu harga pedet sangat menjadi penentu tingkat keuntungan penggaduh. Pada kenyataannya harga jual pedet tidak mencapai nilai BEP. Penjulan pedet jantan memiliki nilai maksimal sebesar Rp 8.500.000,00 sedangkan pedet betina tidak boleh diperjual belikan. Kondisi ini tentu akan memperburuk arus penerimaan peternak. 


\section{Kriteria investasi}

\section{Net Present Value (NPV)}

Berdasarkan Tabel 6, dapat diindikasikan bahwa usaha penggaduh dinyatakan tidak layak dikarenakan NPV kurang dari 1. Nilai NPV ini disebabkan karena inflow yang lebih rendah dari pada outflow. Berbeda dengan usaha ternak pada sector penggemukan dengan pola gaduhan, program sapi potong gaduhan memberikan manfaat dalam hal peningkatan populasi, penyerapan tenaga kerja dan peningkatan pendapatan terhadap peternak dengan nilai NPV diatas 1 (Yowel 2011)

\section{Internal Rate of Return (IRR)}

Usaha pembibitan memiliki nilai IRR yang jauh lebih kecil dari pada DR, hal ini mengindikasikan bahwa usaha pola gaduhan responden tidak layak untuk dilaksanakan. Matondang dan Rusdiana (2013) menyatakan bahwa Performance usaha pembibitan sapi potong beragam di masingmasing daerah. Akan tetapi dengan investasi yang kecil program pembibitan sapi potong berbasis peternakan rakyat sulit dilakukan di Indonesia dengan mayoritas peternak berskala kecil.

\section{Net Benefit Cost Ratio (Net B/C Ratio)}

Berdasarkan penilaian kriteria invetasi, Atau dapat dijelaskan bahwa manfaat bersih yang menguntungkan lebih banyak dibandingkan manfaat bersih yang tidak menguntungkan. Kondisi ini menjelaskan bahwa dengan bantuan miliki nilai yang kurang dari satu. Hal ini mengindikasikan bahwa usaha pola gaduhan dinilai tidak layak. Dengan indikasi bahwa manfaat bersih yang menguntungkan bisnis belum dapat menutupi kerugian yang besar.

\section{Gross Benefit Cost Ratio (Gross B/C Ratio)}

Tabel 4, nilai Gross B/C responden lebih kecil dari satu. Dengan kata lain, bahwa usaha tersebut dapat dinyatakan tidak layak untuk tetap diusahakan. Hal ini mengindikasikan bahwa tambahan biaya tidak menyebabkan tambahan manfaat yang diterima.

\section{Tabel 4. Kriteria investasi responden}

\begin{tabular}{lr}
\hline \multicolumn{1}{c}{ Kriteria Investasi } & Besaran \\
\hline NPV (Rp) & $(911019851)$ \\
Net B/C & 0.23 \\
Gross BC & 0.83 \\
IRR (\%) & -38.26 \\
\hline
\end{tabular}

116 | Ridha Rizki Novanda; Analisis Kelayakan Finansial Pembibitan Sapi ... 


\section{SIMPULAN DAN SARAN}

\section{Simpulan}

Usaha pembibitan sapi Peranakan ongole dengan pola gaduhan secara finansial dinilai tidak layak karena tidak memenuhi standar kelayakan baik NPV, Net B/C, Gross BC dan IRR

\section{Saran}

Berdasarkan hasil analisis yang telah dilakukan terkait dengan kelayakan usaha penggaduh, maka dapat disarankan sebagai berikut :

a. Sebaiknya dilakukan perbaikan terhadap sistem IB yang masih memiliki kelemahan menghasilkan S/C yang lebih besar dari standar

b. Sebaiknya pola gaduhan dari dana bantuan sosial tidak diterapkan karena kurang menguntungkan bagi masyarakat

c. Diperlukan bantuan perluasan kawasan hijauan untuk peternak di Desa Bleberan. Hal ini dikarenakan hutan rakyat dan tegalan belum bisa mencukupi kebutuhan hijauan peternak sehingga harga hijauan masih mahal

d. Sebaiknya terdapat penstandaran harga pedet lokal dan impor, agar posisi pedet lokal bisa meningkat dipasaran dan harganya juga dapat meningkat

\section{DAFTAR PUSTAKA}

Armunanto, Jum'atri Y, Cepriadi. 2014. Analisis Usaha Sapi Potong dengan Pola Kemitraan antara Investor (pemodal) dengan Petani Peternak (penggaduh) di Kelurahan Sail Kecamatan Tenayan raya Kota Pekan Baru. JOM FAPERTA. 1 (2): 1-14

Atmakusuma J, Sarianti T, Ristianinjgrum A. 2011. Analisis Kelayakan Usaha Pembibitan dan penggemukan sapi potong Dalam Rangka swasembada

Daging Sapi Nasional. Di dalam : Proseding seminar Penelitian Unggulan

Departemen Agribisnis. Bogor (ID) : hlm 141-157

[BPS] Badan Pusat Statistik. 2013. Sensus Pertanian Populasi Sapi Potong Daerah Istimewa Yogyakarta Menurut Wilayah dan Jenis Ternaknya [Internet]. [diunduh pada 2014 Septemberr 17]. Tersedia pada:

http://st2013.bps.go.id/dev2/index.php/site/Tabel?tid=50\&wid $=340$ $\underline{0000000}$

[BPS] Badan Pusat Statistik. 2013. Sensus Pertanian Populasi Sapi Potong Daerah Istimewa Yogyakarta Jumlah Rumah Tangga Usaha Ternak dan Jumlah Jenis Ternak yang Diusahakan [Internet]. [diunduh pada 2014 Septemberr 17]. Tersedia pada: 
http://st2013.bps.go.id/dev2/index.php/ site/Tabel?tid=52\&wid=340 $\underline{0000000}$

Johan. 2010. Analisis Finansial Usaha ternak Sapi Potong Pola Gaduhan di Kecamatan Kairatu Kabupaten Seram. J Agroforesti. 5 (3) :187-191

Matondang H, Rusdiana R. 2013. Langkah- langkah Strategis Dalam Mencapai Swasembada Daging Sapi/Kerbau 2014. J Litbang Pert. 32 (3)

Septiandi H. 2013. Analisis Keuntungan Pada Sistem Gaduhan tternak Sapi Bali di Kecamatan Walenrang Utara Kabupaten Luwu[skripsi]. makasar [ID]: Universitas Hasanudin

Widianti R. 2012. Kelayakan Finansial usaha sapi potong pembibitan dengan berbagai bantuan modal di pedesaan Kabupaten Gunung Kidul Daerah Istimewa Yogyakarta. Buletin Peternakan. 36 (2): 122-128

Yowel L, Krishna A, dan Panjono. 2011. Evaluasi Program Pengembangan Sapi Potong gaduhan Melalui Kelompok di Kabupaten Manokwari Papua Barat. Buletin Peternakan. 35 (3): 208-217

Zulfamita, Made A, dan Sudi N. 2009. Evaluasi kelayakan Usaha Penggemukan Sapi potong Gaduhan di desa Grantung Kecmatan Bayan Kabupaten Purworejo. Buletin Peternakan 33(1):57-63 